\title{
General anesthetic versus light sedation: Effect on pediatric endoscopy wait times
}

\author{
Christine Edwards BSc ${ }^{1}$, Vikram Kapoor $\mathrm{MD}^{2}$, Christopher Samuel MD ${ }^{3}$, \\ Robert Issenman MD FRCPC ${ }^{1}$, Herbert Brill MD MBA FRCPC ${ }^{1}$
}

\begin{abstract}
C Edwards, V Kapoor, C Samuel, R Issenman, H Brill. General anesthetic versus light sedation: Effect on pediatric endoscopy wait times. Can J Gastroenterol 2013;27(9):519-522.
\end{abstract}

BACKGROUND: Wait times are an important measure of health care system effectiveness. There are no studies describing wait times in pediatric gastroenterology for either outpatient visits or endoscopy. Pediatric endoscopy is performed under light sedation or general anesthesia. The latter is hypothesized to be associated with a longer wait time due to practical limits on access to anesthesia in the Canadian health care system.

OBJECTIVE: To identify wait time differences according to sedation type and measure adverse clinical outcomes that may arise from increased wait time to endoscopy in pediatric patients.

METHODS: The present study was a retrospective review of medical charts of all patients $<18$ years of age who had been assessed in the pediatric gastroenterology clinic and were scheduled for an elective outpatient endoscopic procedure at McMaster Children's Hospital (Hamilton, Ontario) between January 2006 and December 2007. The primary outcome measure was time between clinic visit and date of endoscopy. Secondary outcome measures included other defined waiting periods and complications while waiting, such as emergency room visits and hospital admissions.

RESULTS: The median wait time to procedure was 64 days for general anesthesia patients and 22 days for patients who underwent light sedation $(\mathrm{P}<0.0001)$. There was no significant difference between the two groups with regard to the number of emergency room visits or hospital admissions, both pre- and postendoscopy.

CONCLUSIONS: Due to the lack of pediatric anesthetic resources, patients who were administered general anesthesia experienced a longer wait time for endoscopy compared with patients who underwent light sedation. This did not result in adverse clinical outcomes in this population.

Key Words: Endoscopy; Gastroenterology; Pediatrics; Procedural sedation; Wait time

$\mathrm{W}$ ait times are viewed by various stakeholders to be a measure of effectiveness in a health care system (1). Concern over excessive wait times in Canada has prompted government initiatives for selected services, as evidenced by the Ontario Wait Time Strategy. This initiative facilitated public access to wait time information in cancer surgery, cardiac procedures, cataract surgery, hip and knee replacements, and diagnostic imaging, and provided increased funding to reduce wait times in these areas (2). The reasons certain services were selected over others are complex, but the availability of wait time data had demonstrable impact on the choice of targets. The Canadian federal government stipulated that these wait time initiatives in target surgeries should not increase wait times for other surgeries. To monitor for such an effect, wait times for various pediatric surgical subspecialty consultations and surgeries have been developed; however, wait times for pediatric endoscopy were not included (3).

\section{L'anesthésie générale ou la légère sédation : l'effet sur les temps d'attente en endoscopie pédiatrique}

HISTORIQUE : Les temps d'attente représentent une mesure importante de l'efficacité du système de santé. Aucune étude ne décrit les temps d'attente en gastroentérologie pédiatrique, que ce soit pour avoir rendez-vous en consultations externes ou pour subir une endoscopie. L'endoscopie pédiatrique est effectuée sous légère sédation ou sous anesthésie générale. Les auteurs postulent que la deuxième intervention s'associe à un temps d'attente plus long, attribuable aux limites pratiques d'accès à l'anesthésie au sein du système de santé canadien.

OBJECTIF : Déterminer les différences de temps d'attente selon le type de sédation et mesurer les issues cliniques indésirables qui peuvent découler d'une augmentation des temps d'attente en endoscopie pour les patients d'âge pédiatrique.

MÉTHODOLOGIE : La présente étude était une analyse rétrospective des dossiers médicaux de tous les patients de moins de 18 ans qui avaient été évalués à la clinique de gastroentérologie pédiatrique et qui devaient subir une endoscopie non urgente en consultations externes au McMaster Children's Hospital de Hamilton, en Ontario, entre janvier 2006 et décembre 2007. La mesure d'issue primaire était le délai entre la visite en clinique et la date de l'endoscopie. Les mesures d'issues secondaires incluaient d'autres périodes d'attente définies et les complications pendant l'attente, telles que les consultations à l'urgence et les hospitalisations.

RÉSULTATS : Le délai d'attente médian avant l'intervention était de 64 jours pour les patients sous anesthésie générale, et de 22 jours pour ceux qui subissaient seulement une légère sédation $(\mathrm{P}<0,0001)$. Les chercheurs n'ont pas constaté de différence significative entre les deux groupes pour ce qui est du nombre de consultations à l'urgence ou des hospitalisations, que ce soit avant ou après l'endoscopie.

CONCLUSIONS : En raison de la pénurie de ressources anesthésiques en pédiatrie, le délai avant de subir l'endoscopie était plus long pour les patients en attente d'une anesthésie générale que pour ceux en attente d'une légère sédation. Cette population n'a pas souffert d'issues cliniques négatives à cause de cette situation.

In the absence of information on wait time in gastroenterology (GI), the Canadian Association of Gastroenterology (CAG) established consensus targets for appropriate wait times for adults in 2005 (4). In 2008, the Survey of Access to Gastroenterology in Canada (SAGE) study analyzed whether these consensus targets were being met. This study identified two types of wait lists central to GI: one for specialist consultation and one for diagnostic procedures (5). It was concluded that both wait lists were longer than published consensus targets, and this was also demonstrated in other studies (5-8).

Despite valuable conclusions made by the SAGE study, its results were limited by several factors. First, the data were collected during a one-week period and may not be representative of wait times yearround. Furthermore, only 17 of $226(7.5 \%)$ participants practiced pediatric GI and the results reported excluded their submissions. Therefore, it is unclear whether patients referred to pediatric GI

${ }^{1}$ McMaster Children's Hospital, McMaster University, Hamilton; ${ }^{2}$ Brampton Civic Hospital, William Osler Health System, Brampton; ${ }^{3}$ Department of

Family \& Community Medicine, University of Toronto, Toronto, Ontario

Correspondence: Dr Herbert Brill, McMaster University, 1280 Main Street West, Hamilton, Ontario L8S 4L8.

Telephone 905-527-2299 ext 75637, e-mail brillh@mcmaster.ca

Received for publication December 20, 2011. Accepted May 12, 2013 
TABLE 1

Patient demographics according to sedation type

\begin{tabular}{lccc}
\hline & $\begin{array}{c}\text { General anesthetic } \\
(\mathbf{n}=\mathbf{1 4 5})\end{array}$ & $\begin{array}{c}\text { Light sedation } \\
(\mathbf{n}=\mathbf{2 4 1})\end{array}$ & $\mathbf{P}$ \\
\hline Age $^{*}$ at & All: $7.2(0.7-16.9)$ & All: $14.1(1.4-17.8)$ & $<0.0001$ \\
consult, & Male $(\mathrm{n}=86):$ & Male $(\mathrm{n}=116):$ & $<0.0001$ \\
years & $7.2(0.7-16.8)$ & $14.2(2.1-17.8)$ & \\
& Female $(\mathrm{n}=59):$ & Female $(\mathrm{n}=125):$ & $<0.0001$ \\
& $7.1(1.2-16.9)$ & $14.0(1.4-17.8)$ & \\
Female & $59 / 145(40.7)$ & $125 / 241(51.9)$ & 0.0429 \\
sex, $\mathrm{n} / \mathrm{n}(\%)$ & & & \\
\hline
\end{tabular}

${ }^{*}$ Data presented as median $(95 \% \mathrm{Cl})$ unless otherwise indicated

specialists experience excessive wait times, as is apparent with adult GI-referred patients (5).

Wait times for gastrointestinal endoscopy may be examined as one measure of wait time in pediatric GI. Endoscopy serves as a diagnostic test for the evaluation of several gastrointestinal complaints in children (9-11). The overwhelming majority of children and adolescents require sedation to successfully complete endoscopic procedures. Two types of sedation may be administered: light sedation or general anesthesia (GA). The latter requires an independent physician (usually an anesthetist) to administer sedative medications and monitor the patient's respiratory status while the endoscopist performs the procedure.

Additional resources required to monitor patients can restrict access to service in a time of budget constraints. The type of sedation chosen for endoscopy is influenced by several factors including patient age, physical status, cognitive level and clinical condition. Hospital staffing, access to anesthesia and patient volume also play a role in the type of sedation chosen $(11,12)$. It was hypothesized that the wait time for GA-facilitated procedures would be longer due to limits on anesthetist availability at McMaster Children's Hospital (Hamilton, Ontario) for the period reported. There are no studies in the medical literature describing wait times for endoscopy involving children and, thus, the implications, extent of wait and causes of long wait times remain unknown.

Given the paucity of data, the aim of the present study was to report wait times in pediatric endoscopy according to sedation type and describe adverse events that may arise from waiting.

\section{METHODS}

Subject selection

The present study was approved by the Ethics Committee of McMaster University. All patients $<18$ years of age who underwent an outpatient endoscopic procedure were included. Patients must have first been referred to the pediatric GI clinic as outpatients and then scheduled for endoscopy after assessment by a pediatric gastroenterologist. Individuals examined by pediatric surgeons or by adult gastroenterologists were excluded. Individuals who presented as inpatients were excluded. Patients who were first assessed in clinic on the same day of endoscopy or at a preoperative visit were also excluded because they were not part of the usual queue that applies to most patients.

\section{Study design}

The present study was a retrospective review of patients undergoing endoscopy from January 2006 to December 2007 inclusive. Data from medical charts, including age, sex and clinical characteristics, were extracted according to type of sedation. The primary outcome measure was to determine the wait time from clinic visit to endoscopy. Secondary outcome measures included other defined wait periods (wait time to diagnosis, total wait time) as well as negative clinical consequences that may arise from waiting such as emergency room visits and hospital admissions. The primary outcome measure was calculated by recording the date of consultation visit and date of endoscopy. Secondary outcome measures were obtained by recording
TABLE 2

Indications for endoscopy according to sedation type

\begin{tabular}{lcc}
\hline Indication & $\begin{array}{c}\text { General anesthesia } \\
(\mathbf{n}=\mathbf{1 4 5})\end{array}$ & $\begin{array}{c}\text { Light sedation } \\
(\mathbf{n}=\mathbf{2 4 1})\end{array}$ \\
\hline Active IBD & $3(2.1)$ & $11(4.6)$ \\
Chronic diarrhea & $20(13.8)$ & $18(7.5)$ \\
Rectal bleeding & $19(13.1)$ & $20(8.3)$ \\
Reflux & $27(18.6)$ & $44(18.3)$ \\
Rule out eosinophilic esophagitis & $6(4.1)$ & $2(0.8)$ \\
Abdominal pain & $12(8.3)$ & $59(24.4)$ \\
Dyspepsia & $0(0)$ & $1(0.4)$ \\
Weight loss & $1(0.7)$ & $2(0.8)$ \\
Regurgitation & $0(0)$ & $3(1.2)$ \\
Dysphagia & $8(5.5)$ & $9(3.7)$ \\
Familial adenomatous polyposis & $1(0.7)$ & $4(1.7)$ \\
Rule out celiac disease & $37(25.5)$ & $22(9.1)$ \\
Failure to thrive & $7(4.8)$ & $0(0)$ \\
Hematemesis & $1(0.7)$ & $5(2.1)$ \\
Follow-up of IBD & $2(1.4)$ & $23(9.5)$ \\
Epigastric pain & $1(0.7)$ & $7(2.9)$ \\
Vomiting/nausea & $2(1.4)$ & $3(1.2)$ \\
Other & $8(5.55)$ & $8(3.3)$ \\
\hline
\end{tabular}

Data presented as n (\%). IBD Inflammatory bowel disease

date of medical/pathological diagnosis, emergency room visits and hospital admissions before and postendoscopy related to gastrointestinal problems. Information regarding cancellations and lack of follow-up visit were also recorded.

Wait time to procedure was defined as the time from clinic visit to completion of endoscopy. Wait time to diagnosis was defined as the time from endoscopy to signing of the pathology report. Total wait time was defined as the time from clinic visit until the signing of the pathology report (this is the time at which the medical diagnosis was made). Emergency room visits and hospital admissions before endoscopy were defined as visits between date of consult and date of endoscopy. Visits and admissions postendoscopy were defined as visits between date of endoscopy and date of follow-up visit.

\section{Data analysis}

Individuals were grouped according to type of sedation. Descriptive statistics were used to report results using medians, means, SD and range to describe continuous variables, and proportions to describe noncontinuous variables. A spreadsheet (Excel, Microsoft Corporation, USA) was used to organize and calculate results. The Student's $t$ test was used for comparisons involving age and wait times. The $\chi^{2}$ test was used for comparisons involving sex, emergency room visits and hospital admissions. Statistical significance was denoted using a two-tailed test with $\mathrm{P}<0.05$.

\section{Patient population}

\section{RESULTS}

A total of 386 subjects met the inclusion criteria, corresponding to 145 endoscopies under GA and 241 endoscopies under light sedation. Demographic information of subjects according to sedation type (light sedation versus GA) is reported in Table 1 . The mean age at consult was 7.2 years in the GA group and 14.1 years in the light sedation group $(\mathrm{P}<0.0001)$. There were significantly more females in the light sedation population ( 125 versus $59 ; \mathrm{P}=0.0429$ ). Indications for endoscopy, final medical diagnosis and final pathological diagnosis according to sedation type are reported in Tables 2 to 4 .

Wait time differences according to sedation type

Median wait times according to sedation type are summarized in Table 5. Patients who were administered GA experienced a significantly longer 
TABLE 3

Final medical diagnosis according to sedation type

\begin{tabular}{lcc}
\hline Medical diagnosis & $\begin{array}{c}\text { General anesthesia } \\
(\mathbf{n}=\mathbf{1 4 5})\end{array}$ & $\begin{array}{c}\text { Light sedation } \\
(\mathbf{n}=\mathbf{2 4 1})\end{array}$ \\
\hline Normal & $17(11.7)$ & $10(4.1)$ \\
Crohn disease & $7(4.8)$ & $46(19.1)$ \\
Ulcerative colitis & $4(2.8)$ & $19(7.9)$ \\
Polyp & $4(2.8)$ & $4(1.7)$ \\
Gastritis & $5(3.4)$ & $12(5.0)$ \\
Reflux esophagitis & $15(10.3)$ & $20(8.3)$ \\
GERD & $21(14.4)$ & $34(14.1)$ \\
Irritable bowel syndrome & $3(2.1)$ & $15(6.2)$ \\
Eosinophilic esophagitis & $9(6.2)$ & $10(4.1)$ \\
Celiac disease & $28(19.3)$ & $17(7.1)$ \\
Dyspepsia & $5(3.4)$ & $11(4.6)$ \\
\hline
\end{tabular}

Data presented as n (\%). GERD Gastroesophageal reflux disease

TABLE 4

Final pathological diagnosis according to sedation type

\begin{tabular}{lcc}
\hline Pathological diagnosis & $\begin{array}{c}\text { General anesthesia } \\
(\mathbf{n}=\mathbf{1 4 3})\end{array}$ & $\begin{array}{c}\text { Light sedation } \\
(\mathbf{n}=\mathbf{2 3 8})\end{array}$ \\
\hline Normal & $66(46.1)$ & $103(43.3)$ \\
Crohn disease & $4(2.8)$ & $29(11.7)$ \\
Ulcerative colitis & $3(2.1)$ & $19(8.0)$ \\
Polyp & $3(2.1)$ & $3(1.3)$ \\
Gastritis & $8(5.6)$ & $16(6.7)$ \\
Reflux esophagitis & $16(11.2)$ & $25(10.5)$ \\
GERD & $2(1.4)$ & $4(1.7)$ \\
Eosinophilic esophagitis & $8(5.6)$ & $8(3.4)$ \\
Celiac disease & $25(17.5)$ & $13(5.5)$ \\
\hline
\end{tabular}

Data presented as $n$ (\%). GERD Gastroesphageal reflux disease

TABLE 5

Wait time according to sedation type

\begin{tabular}{lccc}
\hline Wait time, days & General anesthesia & Light sedation & $\mathbf{P}$ \\
\hline To procedure & $64.0(5-230)$ & $22.0(1-180)$ & $<0.0001$ \\
To diagnosis & $6.0(2-20)$ & $2.0(1-14)$ & $<0.0001$ \\
Total & $69.0(10-235)$ & $25.0(2-185)$ & $<0.0001$ \\
\hline
\end{tabular}

Data presented as median (range) unless otherwise indicated

wait time than patients administered light sedation. Median wait time to procedure was 64 days for GA compared with 22 days for light sedation $(\mathrm{P}<0.0001)$. Wait time to diagnosis was six days for $\mathrm{GA}$ compared with two days for light sedation $(\mathrm{P}<0.0001)$. Total wait time was 69 days for GA compared with 25 days for light sedation $(\mathrm{P}<0.001)$.

Adverse events of waiting

Adverse events of waiting, reported as emergency room visits and hospital admissions before and postendoscopy, are shown in Table 6 . There were no significant differences in the number of hospital admissions and emergency room visits according to sedation type. Reasons for emergency room visits and hospital admissions are reported in Table 7 .

\section{Comparison with CAG consensus targets}

Wait times to procedure are compared with CAG consensus targets according to sedation type in Table 8. Wait times for endoscopies under light sedation met consensus targets; however, wait times for endoscopies performed under GA exceeded these targets.

Cancellations and failure to follow-up

Overall, five patients cancelled endoscopic procedures due to resolution of symptoms $(n=1)$, illness $(n=3)$ and anxiety $(n=1)$. Thirty-five patients did not have a follow-up clinic visit, and the reasons in each case were difficult to ascertain.
TABLE 6

Health outcomes differences according to sedation type

\begin{tabular}{lccc}
\hline & $\begin{array}{c}\text { General } \\
\text { anesthesia }\end{array}$ & $\begin{array}{c}\text { Light } \\
\text { sedation }\end{array}$ & $\mathbf{P}$ \\
\hline Admissions before endoscopy & $2(1.4)$ & $3(1.7)$ & 0.7286 \\
Admissions postendoscopy & $2(1.4)$ & $4(1.7)$ & 0.8344 \\
ER visits before endoscopy & $2(1.4)$ & $3(1.7)$ & 0.7286 \\
ER visits after endoscopy & $2(1.4)$ & $2(0.8)$ & 0.9984 \\
\hline
\end{tabular}

Data presented as $n(\%)$ unless otherwise indicated. ER Emergency room

TABLE 7

Reasons for emergency visits and hospital admissions

\begin{tabular}{cll}
\hline & General anesthesia & Light sedation \\
\hline $\begin{array}{l}\text { Admission } \\
\text { before } \\
\text { endoscopy }\end{array}$ & Ulcerative colitis $(n=2)$ & $\begin{array}{l}\text { Crohn disease }(n=2) \\
\text { Ulcerative colitis }(n=1)\end{array}$ \\
$\begin{array}{c}\text { Admissions } \\
\text { after }\end{array}$ & Bowel obstruction $(n=1)$ & Crohn disease $(n=3)$ \\
endoscopy & Fever postendoscopy $(n=1)$ & Bowel perforation $(n=1)$ \\
$\begin{array}{c}\text { ER visits before } \\
\text { endoscopy }\end{array}$ & Clcerative colitis $(n=1)$ & Abdominal pain $(n=2)$ \\
ER visits after & Abdominal pain $(n=1)$ & Difficulty swallowing $(n=1)$ \\
endoscopy & Rectal bleeding $(n=1)$ & Rectal bleed $(n=1)$ \\
& & Postendoscopy abdominal \\
& pain $(n=1)$
\end{tabular}

ER Emergency room

TABLE 8

Comparison of CAG consensus on medically acceptable wait times (2) with pediatric endoscopy wait times

\begin{tabular}{lccc}
\hline & $\begin{array}{c}\text { CAG } \\
\text { consensus }\end{array}$ & $\begin{array}{c}\text { General } \\
\text { anesthesia }\end{array}$ & $\begin{array}{c}\text { Light } \\
\text { sedation }\end{array}$ \\
\hline Active IBD & $<14$ & 44 & 16 \\
Rectal bleeding & $<60$ & 64 & 23 \\
Dysphagia & $<60$ & 70 & 28 \\
Reflux/dyspepsia & $<60$ & 75 & 30 \\
Chronic diarrhea & $<60$ & 69 & 32 \\
Chronic abdominal pain & $<60$ & 60 & 25 \\
Celiac disease & $<60$ & 53 & 30 \\
\hline
\end{tabular}

Data presented as number of days. CAG Canadian Association of Gastroenterology; IBD Inflammatory bowel disease

\section{DISCUSSION}

We report the first study of wait times in pediatric endoscopy. We have illustrated that patients undergoing the procedure with GA experienced a longer total wait time compared with light sedation (69 days versus 25 days, respectively; $\mathrm{P}<0.0001$ ). However, this difference in wait time did not lead to apparent adverse clinical outcomes (increased emergency room visits or hospital admissions) in this population.

The light sedation population was significantly older compared with the GA group due to standardized hospital practice of selecting light sedation for older children and adolescents. The light sedation group had a significantly larger proportion of females for reasons that remain unclear. It may be that adolescent females are considered to be more mature than males of the same age. Previous studies have shown no difference in pain tolerance according to sex $(13,14)$, while others have reported that females are more sensitive and less tolerant to pain (15). In our experience, boys tend to select GA over light sedation when presented with each option. Thus, despite the findings of other studies, it may be that in our sample, boys anticipated pain or anxiety and preferred GA to light sedation.

The sample was large by pediatric endoscopy standards and information was extracted over a two-year period, as opposed to the SAGE study, which was performed over a one-week period. We believe that our results are generalizable to other pediatric GI clinics with limited 
access to pediatric anesthesia across Canada. Compared with the SAGE study, wait times in pediatric GI were similar to wait times in adult GI, which reported an overall median wait time to procedure of 50 days ( $95 \%$ CI 45 to 55 days). In the adult population studied in SAGE, wait times were higher in screening colonoscopy and those referred for surveillance of polyps. In the pediatric population, patients are not referred for endoscopy for screening purposes, but rather because they are symptomatic. Thus, it seems reasonable that wait times in pediatric GI should be shorter than adult wait times (5).

The SAGE study compared its results with the consensus targets established in 2005 and concluded that these targets were not being met in adult GI. Although there is a lack of consensus targets for pediatric endoscopy, our results demonstrate that wait times for young people undergoing endoscopy under GA are longer than adult benchmarks (4), with the exception of celiac disease confirmation. Reasons behind the excessive wait times in pediatric GI remain elusive, but may be related to reallocation of resources (3) or a shortage of GI specialists (16).

There were several limitations to the present study. Given its retrospective nature, we could not ascertain all negative outcomes that may arise from waiting. Aside from emergency room visits and hospital admissions to McMaster Children's Hospital, we could not determine whether patients visited their primary care physician for medical assistance if it was not noted in the outpatient clinic visits. Furthermore, we were not able to capture the impact that waiting had on quality of life. Studies have found that waiting is associated with missed work and increased distress $(7,17,18)$. It is possible that waiting may

\section{REFERENCES}

1. Hadorn D. The Chaoulli challenge: Getting a grip on waiting lists. CMAJ 2005;173:271-3.

2. Ontario Ministry of Health and Long Term Care. Ontario Wait Time Strategy. Last Update October 29, 2010. <www.health.gov.on. ca/en/public/programs/waittimes/strategy.aspx/> (Accessed October $10,2011)$.

3. Wait Time Alliance for Timely Access to Health Care. Pediatric Canadian Access Targets for Surgery (P-CATS). Last Update November 5, $2008<$ www.waittimealliance.ca/wait_times.htm/> (Accessed November 5, 2011).

4. Paterson WG, Depew WT, Paré P, et al. Canadian consensus on medically acceptable wait times for digestive health care. Can J Gastroenterol 2006;20:411-23.

5. Leddin D, Bridges RJ, Morgan DG, et al. Survey of access to gastroenterology in Canada: The SAGE wait times program. Can J Gastroenterol 2010;24:20-5.

6. Leddin D, Armstrong D, Barkun AN, et al. Access to specialist gastroenterology care in Canada: Comparison of wait times and consensus targets. Can J Gastroenterol 2008;22:161-7.

7. Yu D, Hopman WM, Paterson WG. Wait time for endoscopic evaluation at a Canadian tertiary care centre: Comparison with Canadian Association of Gastroenterology targets. Can J Gastroenterol 2008;22:621-6.

8. Armstrong D, Barkun ANG, Chen Y, et al. Wait time for endoscopic evaluation at a Canadian tertiary care centre: Comparison with Canadian Association of Gastroenterology targets. Can J Gastroenterol 2008;22:155-60. negatively influence quality of life in children and parents, although such a study would have to be performed prospectively to validate this notion. Our main concern was to study serious complications that may arise from waiting. We evaluated this by examining emergency room visits and hospital admissions. However, we could only collect hospital visits within the Hamilton Health Sciences hospital network, and it is possible that more symptomatic patients may have visited another hospital while waiting for an endoscopic procedure. Patients and families seen in the pediatric GI clinic are instructed to communicate with the clinic or the on-call pediatric GI service if problems occur; therefore, this potential ascertainment bias was likely minimal. Furthermore, individuals admitted to other hospitals would likely be transferred to Hamilton Health Sciences.

\section{CONCLUSION}

Arranging pediatric endoscopy under GA compared with light sedation results in a longer wait time. No serious health outcomes appeared to arise from the observed wait time. However, for most indications, wait time for endoscopy under GA exceeds the CAG's consensus target for wait time for endoscopy in adults. Given the increasing use of GA or deep sedation for procedures in the pediatric age group, assured access to GA is a prerequisite for a wait time strategy involving any such activities. This is required to allow equity of access for younger patients who require endoscopy, a procedure that is central to diagnosis in many gastrointestinal conditions. A prospective study may yield additional insight into negative health outcomes.

9. Mudawi HM, El Tahir MA, Suleiman SH, et al. Paediatric gastrointestinal endoscopy: Experience in a Sudanese university hospital. East Mediterr Health J 2009;15:1027-31.

10. Gilger MA, Gold BD. Pediatric endoscopy: New information from the PEDS-CORI project. Curr Gastroenterol Rep 2005;7:234-9.

11. Fredette ME, Lightdale JR. Endoscopic sedation in pediatric practice. Gastrointest Endosc Clin N Am 2008;18:739-51, ix.

12. Schwarz SM, Lightdale JR, Liacouras CA. Sedation and anesthesia in pediatric endoscopy: One size does not fit all. J Pediatr Gastroenterol Nutr 2007;44:295-7.

13. Mayer EA, Berman S, Chang L, Naliboff BD. Sex-based differences in gastrointestinal pain. Eur J Pain 2004;8:451-63.

14. Lu Q, Zeltzer LK, Tsao JC, Kim SC, Turk N, Naliboff BD. Heart rate mediation of sex differences in pain tolerance in children. Pain 2005;118:185-93.

15. Riley JL III, Robinson ME, Wise EA, Myers CD, Fillingim RB. Sex differences in the perception of noxious experimental stimuli: A meta-analysis. Pain 1998;74:181-7.

16. Moayyedi P, Tepper J, Hilsden R, Rabeneck L. International comparisons of manpower in gastroenterology. Am J Gastroenterol 2007;102:478-81.

17. Parker J, Kennedy P. Factors predictive of distress in people awaiting a lower gastro-intestinal endoscopy. Psychol Health Med 2010;15:26-33

18. Paterson WG, Barkun AN, Hopman WM, et al. Wait times for gastroenterology consultation in Canada: The patients' perspective. Can J Gastroenterol 2010;24:28-32. 


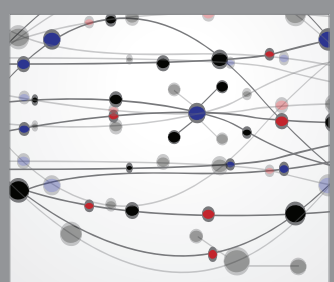

The Scientific World Journal
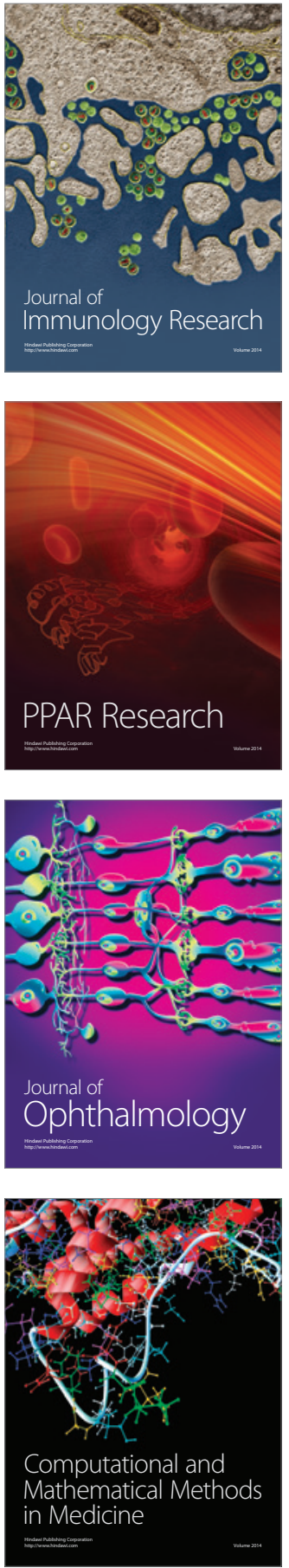

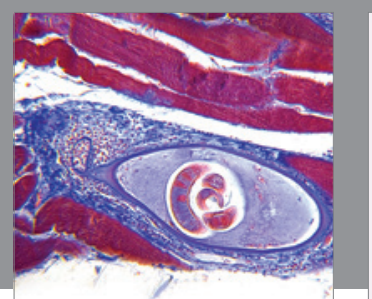

Gastroenterology Research and Practice

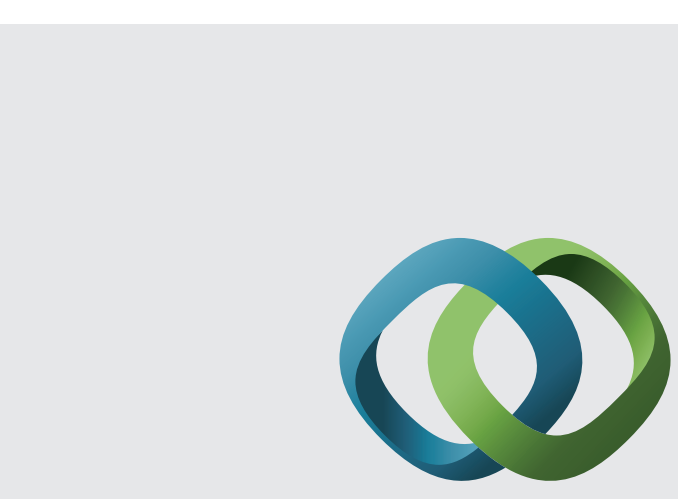

\section{Hindawi}

Submit your manuscripts at

http://www.hindawi.com
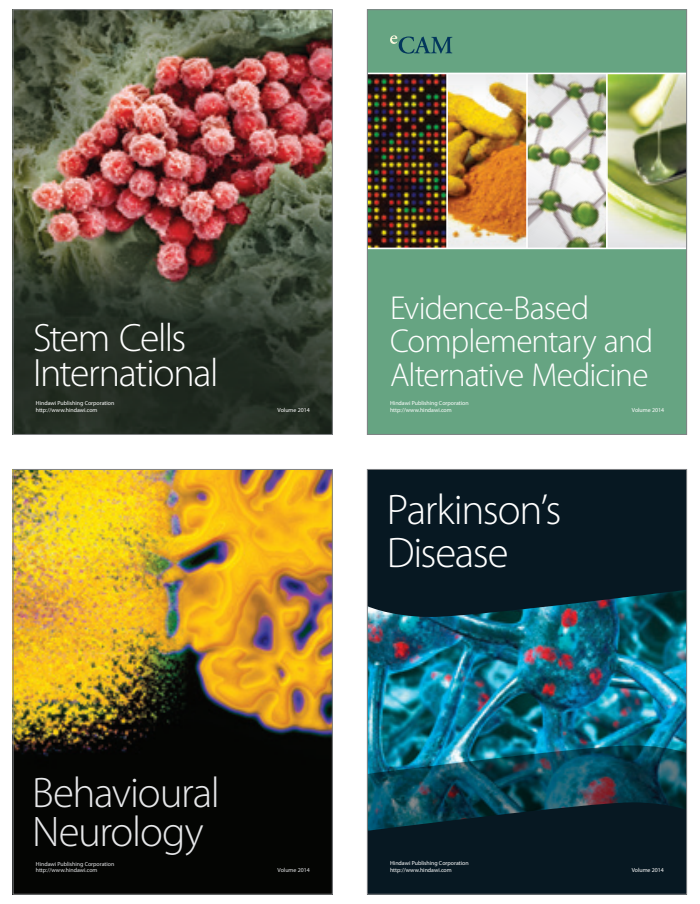
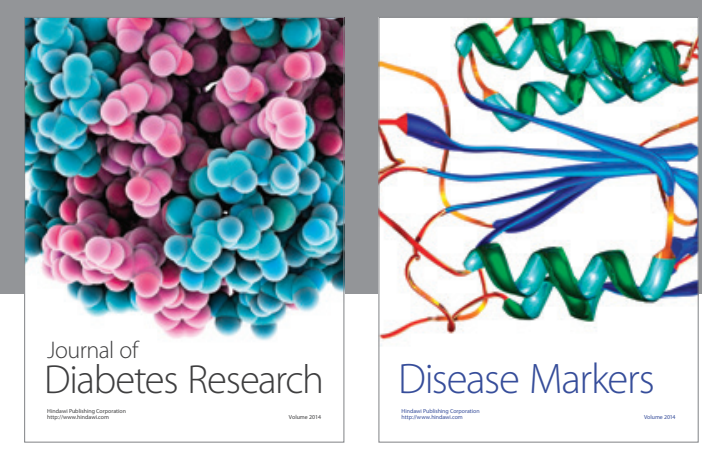

Disease Markers
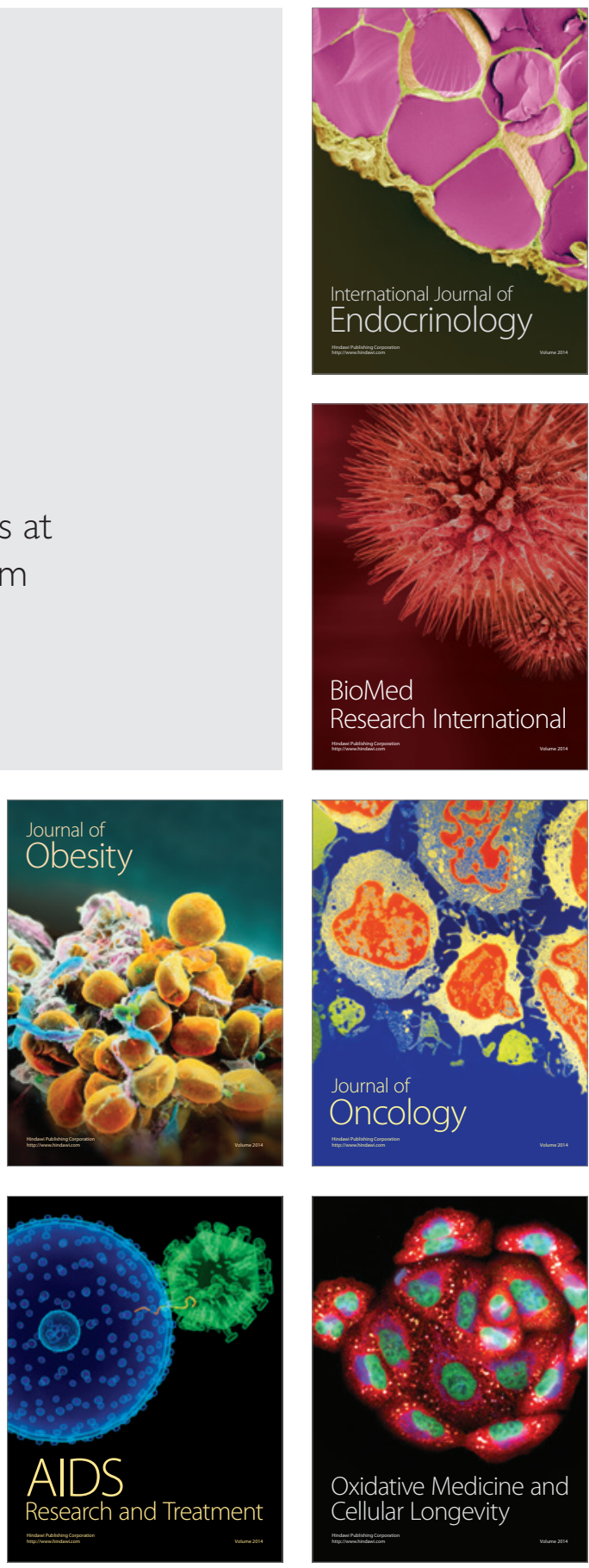